\title{
Construction of Multiple Collaborative Training Mechanism for Innovative and Entrepreneurial Talents in Colleges and Universities
}

\author{
Yue Hao \\ College of Business Administration, Jilin Engineering Normal University, Changchun City, China
}

18792044@qq.com

Keywords: Innovative and entrepreneurial talents; Collaborative innovation; Multiple collaboration; Training mechanism

\begin{abstract}
The "multiple collaborative" training of innovative and entrepreneurial talents in colleges and universities includes both the school and external collaborative training, and the collaborative training within the school, which is the unity of the external collaborative training and internal collaborative training. The external collaborative training means that through the breakthrough of the barriers among different social subjects such as government, universities, industries and enterprises, a network system of interaction and cooperation is formed in order to achieve the collaborative effect of talent training. The collaborative training in school refers to the collaboration, complementation and cooperation of different elements related to the training of innovative and entrepreneurial talents and different departments in school, so as to realize the optimal allocation of resources and the optimal synchronization of action. In order to realize the effective operation of the "multiple collaborative" training mechanism for innovative and entrepreneurial talents in colleges and universities, it is necessary to perfect relevant systems and innovate in practice.
\end{abstract}

\section{Introduction}

The training of innovative and entrepreneurial talents is a systematic and complex social project. To achieve this project with high quality, it requires the collaborative training of the government, universities, industries and enterprises. In China, the training of innovative and entrepreneurial talents is a new thing. The social organizations such as government, universities, industries and enterprises have not yet formed a joint force, so there is a disconnection in the training mechanism. Therefore, how to build the "multiple collaborative" training mechanism of innovative and entrepreneurial talents has become an urgent question to be answered urgently in the training of innovative and entrepreneurial talents in colleges and universities.

\section{The Theoretical Basis of "Multiple Collaborative" Training Mechanism-Collaborative Innovation}

Collaborative innovation is the diffusion and application of synergetic theory in the field of scientific and technological innovation, which is to construct different innovative elements into a dynamic operating survival system. The resources sharing and optimal allocation are established among the various elements, and the collaborative effect of the innovation field is finally produced[1]. The proposal of this theory is to introduce the collaborative thought into the innovation process, so that the innovation activities can be changed qualitatively through the mechanism interaction on the basis of each innovative subject playing their respective roles and improving their efficiency. The collaborative innovation theory has rich connotation, which is concretely embodied in the talent training, showing as collaborative education. Collaborative education is an effective interaction among different educational subjects in sharing resources and accumulating energy in the system with the aim of training talents. Collaborative education is the proper meaning of collaborative innovation. Under the leading of the government, there are two objectives for collaborative innovation between schools, industries and enterprises. One is the talents training and use, and the other is the technical research and development and the knowledge 
value added. The purpose of these two aspects is closely linked and can not be separated. If they are separated, the various elements of the system will not be able to interact effectively and produce collaborative effects. Collaborative education enriches the connotation of collaborative innovation. Based on the theory of collaborative innovation, the author believes that "multiple collaborative" training mechanism is an important way to cultivate innovative and entrepreneurial talents and achieve collaborative education.

\section{The Basic Connotation and Practical Significance of "Multiple Collaborative" Training Mechanism}

The basic connotation of the "multiple collaborative" training mechanism is in the social field. The term "mechanism" refers to the interrelationship and interaction between different parts of the social system, as well as the internal working way of promoting, maintaining and restricting the operation of the system. The talent training mechanism is a regular mode of operation in the process of talent training, and is the interrelation between related elements, the restriction and promotion[2]. The "collaborative" can refer to the coordination and cooperation of the elements within an organization to achieve the goals of the organization, and also refer to the cooperation between the participants among organizations for greater goals. Therefore, we believe that the "multiple collaborative" training mechanism of innovative and entrepreneurial talents is the restriction and promoting mechanism of mutual influence and interaction among the relevant factors of talent training under the requirements and objectives of the training of innovative and entrepreneurial talents, and it is the sum total of the interactive relationship formed between universities and the external environment, as well as the internal factors of universities. The "multiple collaborative" training of innovative and entrepreneurial talents includes both the school and external collaborative training, that is the collaborative training among different social subjects such as the government, universities, industries and enterprises, and the collaborative training within the school, that is the collaborative training between various elements related to the training of the innovative and entrepreneurial talents in the school, which is the unity of internal collaborative training and external collaborative training in universities. The collaborative training within the school refers to the collaboration, complementation, and cooperation of different elements related to the training of innovative and entrepreneurial talents and different departments in school, so as to realize the optimal allocation of resources and the optimal synchronization of action[3].

\section{Construction of "Multiple Collaborative" Training Mechanism System}

Regardless of the external collaborative training and internal collaborative training, it contains different sub mechanisms, and the role of each mechanism needs the support and coordination of other sub mechanisms. The different sub mechanisms of mutual coordination and mutual promotion constitute "multiple collaborative" training mechanism system, thus forming an orderly structure of the system in order to achieve a collaborative goal. The key to the orderly operation of innovation and entrepreneurship talents training lies in the collaboration among these sub mechanisms[4].

External Collaborative Training Mechanism System. The external collaboration, which takes the government, universities, industries and enterprises as the main body, is the strategic coordination across organizations. In essence, it is a dynamic and open collaborative talent training system which consists of four subsystems, such as the government, universities, industries and enterprises. Deep involvement in the training process mechanism.

The first is the education resources co-construction and sharing mechanism. The lack of training ability caused by lack of resources is an important problem for the training of innovative and entrepreneurial talents in colleges and universities. The important purpose of training talents jointly by the government, schools, industries and enterprises is to realize the joint development, utilization and sharing of education resources. Government, universities, industries and enterprises have different resource advantages, and resources should be shared in the collaborative training of talents. The government makes use of the advantages of formulating policies, coordinating 
functions and financial resources to regularly release the talent demand plan to provide the basis for the social demand for the college major adjustment, uses policy and financial support to encourage and support enterprises to participate in school talent training, especially for accepting college students' internship, and uses the coordination function to build a political-school-enterprise cooperation talent training platform. Colleges and universities have rich educational resources, have strong technical advantages and talent advantages. On the one hand, the universities should cultivate the talents to meet the needs of local economic and social development and the needs of the development of cooperative enterprises. At the same time, the school education resources should be used to train the local government and the employees of the cooperative enterprises and to serve the life-long education[5]. On the other hand, the technical and intellectual advantages should be given full play for local economic transformation, industrial upgrading, and the technological innovation, product upgrading and management improvement of cooperative enterprises. The industry, as a kind of intermediary organization, on the one hand, should feed back the development needs of related industries and the ability demand of industrial enterprises to talents to universities to guide the reform of talent training in colleges and universities. At the same time, the bridge operations should be given full play to promote communication and cooperation between the government, universities and enterprises. The enterprise has a real environment of practice, with advanced technology and equipment and a large number of innovative entrepreneurs with rich practical experience. It can be built through cooperation as a practical teaching base for students, employment and entrepreneurial bases and an experimental site for the transformation of scientific and technological achievements.

The second is the collaborative construction mechanism of teachers team. At present, the composition of the faculty and the knowledge, ability and quality of professional teachers are far from the requirements of the training of innovative and entrepreneurial talents. The collaborative construction mechanism is a effective way to solve this problem. The first one is to recruit outstanding professionals to enrich the teaching staff. In order to solve the problem of insufficient number of teachers and improve the structure of teachers, when introducing the high level professionals with rich practical experience in the industry to enrich the teachers' team, the relevant professional and technical personnel, senior management personnel, entrepreneurs with rich entrepreneurial experience can be invited to work as part-time teachers in schools[6]. By hiring and employing full-time and part-time teachers with industry and business backgrounds, the problem of insufficient number can be solved and the teacher team can be optimized. The second one is to strengthen the training of innovative and entrepreneurial teachers in schools. Schools should formulate relevant policies to encourage teachers to participate in the innovative and entrepreneurial practice of industry enterprises and scientific research institutes, encourage teachers to participate in the development and research of projects in industrial enterprises, and scientific research institutes, or collaborate on innovation and entrepreneurship projects, and create conditions to support teachers with a strong sense of innovation and entrepreneurship to lead the students to innovation and entrepreneurship.

Internal Collaborative Training Mechanism System. The first one is the collaborative training mechanism in class and after class. The innovative and entrepreneurial talents are essentially practical talents, which require that the innovation and entrepreneurship education must adhere to the principle of combining theoretical learning with practice training, and linking the first classroom with the second classroom. Influenced by traditional concepts and division methods, the first class and the second classroom have been fragmented for a long time, lacking openness and integration[7]. To cultivate innovative and entrepreneurial talents, it is necessary to establish an in-class and extracurricular collaborative training mechanism, so that the first class and the second class can move from relative separation to integration, from single education to collaborative education.

First of all, colleges and universities should establish the concept of in-class and extracurricular collaborative education, clear the goal of cultivating innovative and entrepreneurial talents and clear the goal and function of the first class and the second class. Secondly, according to the goal 
orientation of innovative and entrepreneurial talent training, the first class curriculum training system is innovated and the second class curriculum training system is integrated to form an innovative and entrepreneurial talent training system, which is independent, interpenetrative and intersecting, so that professional education and innovative entrepreneurship education can be integrated. Finally, the platform and bridge that effectively connects the first class and the second class should be built, and the educational functions of experimental teaching platform and off campus practice education base should be expanded to transform the professional education resources into education practice platform for innovation and entrepreneurship, so that the professional education can be integrated with the innovation and entrepreneurship practice.

The second one is the interdisciplinary and cross developmental mechanism. The development of innovative and entrepreneurial talents requires the interdisciplinary and cross-developmental mechanism thus facilitating the shift from the cultivation of talents of the unitary major to the integrative one. First, universities can set up the interdisciplinary professions directly. Setting the interdisciplinary professions in order to cultivate the innovative and entrepreneurial talents is the very common way of cultivating talents and also the common tendency in the undergraduate major construction among many developed countries.[8] The second is to widen the professional scope. One method is to recruit students according to broad categories and then develop them according to their levels. More specifically, in their first two years, students are cultivated according to the general education. While, in the second two years, students are cultivated according to the professions, that is, they can choose the majors and professional preferences. Another method is to build up the platform courses to open up the similar professional courses under the same level discipline or profession, to set up the inter-disciplinary courses, and students can choose the courses for other professions according to their own needs, and the setting of multidisciplinary and optional courses can be enhanced. The third is to implement the double-degree and the major and minor system, thus encouraging students to obtain the second degree or minor other professions in addition to their majors. The fourth is to construct the interdisciplinary experimental classes for developing talents, breaking the disciplinary limits, demonstrating the obvious multidisciplinary quality and high integrity in terms of course setting.

Organizational Guarantee and Institutional Innovation within the School. In a certain sense, the institutional barrier inside the school restrains the multiple collaborative cultivation to a great degree. This barrier restricts not only the collaborative cultivation inside the university but the one outside the university.[9] Therefore, firstly, the open and tolerant modern university institution should be built. As the main body of developing talents, higher schools are supposed to strengthen the inner collaborative training of talents, meanwhile, they are expected to contact the society closely and actively seek the alliance and cooperation with exteriors and expand the school space and provide the development of the innovative and entrepreneurial talents with the fantastic educational environment. Secondly, the scientific and efficient organization and management system should be constructed. The school should set up organizational and administrative coordinating institution for the development of the innovative and entrepreneurial talents. Traditional limits between schools, subjects and professions should be broken. And also the cross-departmental, inter-disciplinary and inter-professional developmental platform of the innovative and entrepreneurial talents should be built up. Thirdly, the internal management system of the school should be reformed and innovated. According to the requirement of the development of the innovative and entrepreneurial talents, schools should actively take the reform and innovation of their institutions. Fourthly, the financial support should be provided for innovation and entrepreneurship education. Higher schools should optimize the expenditure structure, and make an overall arrangement of fund through multiple channels, and support innovative and entrepreneurial education and also innovation and entrepreneurship of the university students.

The System Perfection and Practice Innovation of Industry Enterprises. In terms of the practical situation of industry sectors' engagement in the development of talents, the first is to define the functional location of industry sectors 'engagement in the development of talents, that is to clear out the relationship among the government, higher school and enterprise.[10] The second is 
to build up the sound internal management system of industries, defining the division of the engagement in the development of talents between administrative departments of enterprises and the industry associations. The third is to strengthen the construction, the coordinating and communicational competence of industry associations. As the significant participant in the development of innovative and entrepreneurial talents, enterprises should recognize and treat the industry-university-research cooperation from the point of view of developmental strategy. On the one hand, being in accordance with the principle including complementarity, trustworthiness, strategic fit and cultural similarity, enterprises select the cooperative universities, cooperative content and manner scientifically and reasonably. Meanwhile, enterprises should do the internal institutional innovation so that they can provide institutional and organizational guarantee for the industry-university- research cooperation.

\section{Reference}

[1] Peng Xinbei. Developing innovative talents for regional innovation system . Higher engineering education Research, 2012, (6): 73-76.

[2] Xiang, Sun Youxia and so on. A review of collaborative innovation — based on the perspective of implementation approach. Science and Technology Management Research, 2011, (14): 15-18.

[3] Chen Jing and so on. The driving mechanism of collaborative innovation . echnical economics, 2012, (8): 6-11.

[4] Xu Ping. On the value idea of "cooperative educating people" in higher vocational education . Vocational Education Forum, 2013, (1): 21-23.

[5] He Jinyu. Research on collaborative innovation and cooperative education mode in local newly-built universities . Jinan: Shandong University Press, 2013. 6.

[6] Yang Pin. A study on the mechanism of cultivating and cooperating talents in vocational colleges . China Vocational and technical Education, 2014, (28): 67-71.

[7] Zheng, Wang Fangping. Problems and countermeasures of cultivating innovative talents in local universities in China . Education theory and Practice, 2011, (9): 6-8.

[8] Yin Xiang, Shing. Construction of innovative talents training system for college students . China University Science and Technology, 2015, (3): 75-77.

[9] Yin Wenjia, Wang Huichen. An analysis of the internal mechanism and promotion path of cooperative cultivation of applied innovative talents . China Electric Power Education, 2014, (14): 27-32.

[10] Chen Guixiang. An analysis of the formation of innovative entrepreneurial talents training mechanism with the linkage of universities, governments and enterprises.University education Science, 2015, (1): 42-47. 